\title{
The Effect of Accounting Information System on Organizational Performance in Jordanian Industrial SMEs: The Mediating Role of Knowledge Management
}

\author{
Muhannad Akram Ahmad \\ Faculty of Economics and Administrative Sciences \\ Al Albayt University \\ Mafraq, Jordan. \\ Seif Obeid Al-Shbiel \\ Faculty of Economics and Administrative Sciences \\ Al Albayt University \\ Mafraq, Jordan.
}

\begin{abstract}
While adopting knowledge management can improve firm performance, it is determined by use of accounting information system. Furthermore, it plays mediating role in the relationship between accounting information system and organization performance. This paper employs regression analysis using SPSS 20 to investigate causal relationships among the variables and to examine the mediation of knowledge management. The empirical findings from a survey of 350 employees in SMEs industrial firms in Jordan confirmed that knowledge management exert a mediating effect on the relationship between accounting information system and organization performance. The main implication of the findings for firms is that use accounting information system working are more likely to achieve higher performance, as a result of strengthened knowledge management. The findings offer evidence on relationships among the variables as well as mediating role of knowledge management in effect of accounting information system on firm performance. This paper is useful to management researchers as well as business managers.
\end{abstract}

Keywords: Knowledge Management, Accounting Information System, Organizational Performance.

\section{Introduction}

One of the determinant factors of successful firms is knowledge management as it assists firms in setting up long-term external environments. In the initial part of the 21 st century, the businesses began focusing on knowledge management and as a consequence, it transformed into a well-sought topic, particularly in the field of managerial accounting research. It was evidenced by prior studies that firms that had consistent control of their knowledge and those that integrate such knowledge into their business activities are more likely to achieve superior success (Dayan, 2017). More specifically, Girard \& Girard (2015) revealed that knowledge management works as a coordinating tool that transforms resources into competencies. In other words, the adoption and performance of knowledge management enables firms to realize improved performance (Lawson et al., 2006; Chen \& Huang, 2007).

Moreover, in this background, Accounting Information System (AIS) can play a significant role in helping firms enhance their performance, where prior studies like Ismail (2009) and Effah et al. (2011) stated that the AIS has an important role in enabling the development of firm performance (Harsh, 2015). This goal can be achieved with the firms being responsive to the environmental changes, especially to the revolution in information technology.

In the current times, information technology has become crucial in its use in majority of firms in that it is now almost impossible to achieve competitive advantage and to survive in the market without adopting IT. In this regard, Harash (2015) stated that the most extensively utilized information system is the AIS, particularly when it comes to financial reporting. The knowledge management impacts and the use of AIS on the performance of firms have been studied in many works in distinct models and thus, it is a must to combine both variables in one model of firm performance to examine the causal relationship between the two.

Accordingly, the present study is organized to achieve this objective. The next section addresses the hypothesis development and this is followed by a discussion on research methodology and the development of a conceptual framework. The results are then analyzed and presented, after which the conclusions, managerial implications and study limitations are presented. 


\section{Research Framework and Hypothesis Development}

\subsection{Accounting Information System and Knowledge Management}

Accounting information system refers to a collection of data and processing procedures that generates the required information of the user (Hall, 2012). According to Hall (2012), the basic aim behind accounting information system is to generate accounting information to external individuals and groups like management and operational personnel. Other studies like Zager et al. (2006) relayed that authentic accounting information are obtained from the quality accounting information system while Susanto (2008) stated that the basic role of the accounting information system is to generate qualified accounting information. Moreover, accounting information system was described by Widjajanto (2001) as a collection of human and equipment resources set to transform data obtained into information that is relayed to different decision makers. Also, Mujilan and Madiun (2012) contended that accounting information systems generates the change either manually or through the computer.

The researcher was encouraged to conduct the present study by the high technology performance of disciplines, particularly the accounting information system that supports global companies' information, where the situation is such that majority of software are not effectively utilized for human resource operations, owing to the different knowledge levels - this holds true for both developing and developed nations. Nevertheless, the accounting information system performs with accuracy and reliability on the basis of the level of knowledge management it uses to support the planning and implementation of strategic management. This works towards the development of the company system and its goals indicating that knowledge management works towards the daily management of firms. Moreover, knowledge management in firms enables it to produce long-term competitive advantages that lead to successful business in the ever-changing market environment. Knowledge management is described as the capability of the firm to guide its employees to cooperate in the generation, capture, sharing and leveraging of collective knowledge for improved performance (Lakshman, 2007). Other studies (Wang \& Huynh, 2013) also defined it as the level to which firms adopt their knowledge management, which results in varying knowledge sharing levels and knowledge application levels. In the context of Malaysia, Sori (2009) examined accounting information system (AIS) in the context of ZBMS Sdn. Bhd and the way it contributes to knowledge management. Meanwhile, Khodadi et al. (2014) found a significant relationship between AIS and knowledge management. On the basis of the above discussed studies in literature, the following hypothesis is proposed to be tested;

H1: Accounting information system (AIS) positively influences knowledge management.

\subsection{Accounting Information Systems and Organizational Performance}

Accounting information system comprises of different forms of records and equipments like computers and communication tools, personnel, and closely coordinated reports created for data transformation into information required by financial management In fact, AIS is one of the key component of the current information system (IS) (Abdallah, 2013). The use of AIS and its success have been extensively studied, with current studies focusing on the relationship between organizational performance with the AIS use (e.g., Ismail, 2009; Effah et al., 2011; Harash, 2015). Other studies indicated a positive relationship between the two - where specifically, Zager et al. (2006) and Ismail (2009) revealed that AIS will be effectively used to enhance organizational performance if the systems implementation involved new information. This is supported by Estebanez et al. (2011) who contended that AIS use has a positive effect on organizational performance. The review of the above literature leads to the proposal of the following hypothesis;

$\mathrm{H} 2$ : Accounting information system positively influences organizational performance.

\subsection{Accounting Information Systems and Organizational Performance}

Majority of authors in prior literature conducted an assessment of the influence of KM elements on organizational performance where some of them stressed on the challenge of its measurement (Vuksic et al., 2012). According to other studies (e.g., Chang \& Chuang, 2011; Mills \& Smith, 2011; Hussein et al., 2012) indicated that knowledge elements positively influenced organizational performance while Asli et al. (2013) showed that knowledge management practices directly influenced SMEs performance. Along a similar line of findings, Dalfard et al. (2013) examined the influence of KM on organizational performance of 106 firms and found that KM positively influenced organizational performance of the firms. In a related study, Llorens-Montes et al. (2008) revealed that strategic variables of knowledge including knowledge slack, absorptive capacity and tacitness, had a positive mediating role on the relationship between transformational leadership and organizational performance.

Moreover, McKeen et al. (2009) and Väyrynen, H., (2014) found that KM practices positively and indirectly influenced financial performance and Richey et al. (2009), and McKeen et al. (2009) related the KM positively affected organization outcomes like the innovation of the firm, product improvement and employee improvement. 
Meanwhile, Asli et al. (2013) revealed the positive and direct influence of KM on the organizational performance among SMEs. The review of the above discussed studies leads to the following hypothesis;

H3: Knowledge management positively influences organizational performance.

\subsection{AIS, Knowledge Management and Organizational Performance}

AIS is an antecedent of knowledge management, while the latter may in turn, antecede critical work outcomes like organizational performance - this premise is partially supported by studies (e.g., Sori, 2009; Khodadi et al., 2014) who found that AIS influences performance and contributes to knowledge management, as well $\mathrm{s}$ organizational performance (Asli et al., 2013). These findings may be attributed to the mediating role of knowledge management on the relationship between AIS and organizational performance. Literature on organizational performance shows little empirical evidence about the factors that may mediate the relationship between AIS and OP (e.g., Estebanez et al., 2011; Soudani, 2012), and to compound the matter further, there is lack of studies confirming the relationship between knowledge management and organizational level effectiveness (Ai et al., 2007; Ngah \& Jusoff, 2009). Hence, this study proposes to test the following hypothesis;

H4: Knowledge management mediates the relationship between AIS and organizational performance.

\section{Research Methodology}

\subsection{Research Model and Instrument}

The study's model is presented in Figure 1;

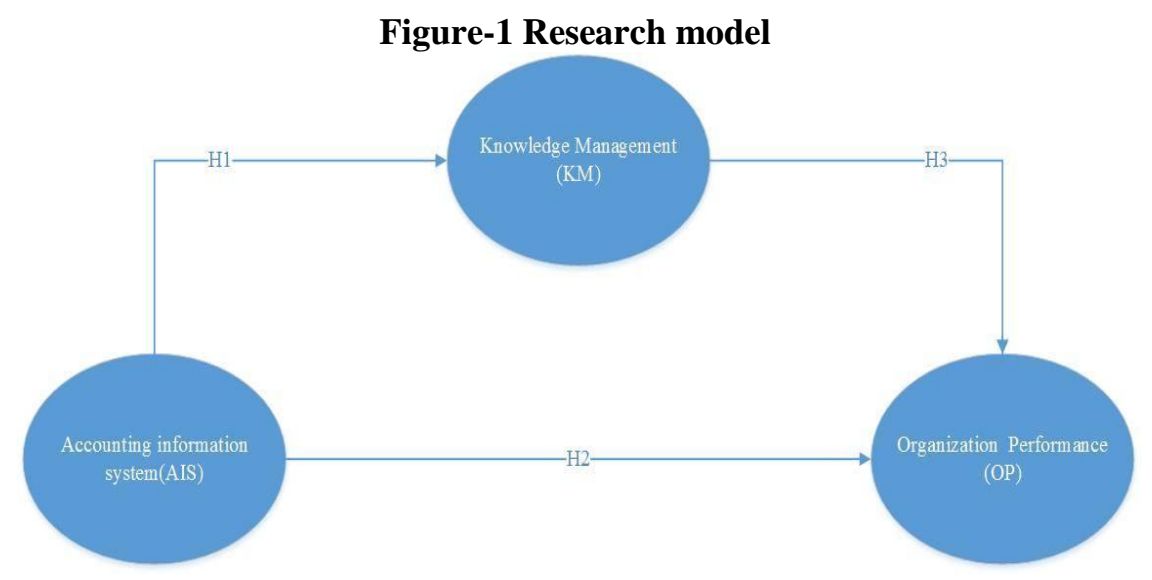

\subsection{Sampling}

The study sample is obtained from the SMEs employees in the Jordanian industrial sector, where a total of 350 questionnaires were distributed, after which the rate of response obtained was around $70 \%$. The study sample demographics show that $78 \%$ of the respondents were front-line employees with 33\% supervisors at the lower level of company hierarchy. Also, $56 \%$ of the sample comprised of male respondents and $44 \%$ were female, $59 \%$ were less than 30 years, $85 \%$ were holders of university degrees, and $55 \%$ had less than 5 years working experience.

\subsection{Questionnaire Design}

The employed research instrument was a structured questionnaire, where the items are measured by a five-point Likert scale ranging from strongly agree to strongly disagree. The variables measured include knowledge management, accounting information system and organizational performance. Following a review of the literature dedicated to knowledge management it was concluded that knowledge management practices items should be obtained from Asli et al. (2013), organizational performance items from ( Pollanen, et al. (2017); Soudani (2012)), and Slavkovic and Babic (2013), and accounting information items from Soudani (2012) and Budiarto and Prabowo (2015).

\section{Data Analysis and Results}

\subsection{Principal Component Analysis}

In this study, the principal component analysis (PCA) coupled with normalized varimax rotation was conducted to confirm the uni-dimensionality of the three primary tools. More specifically, one principal component was obtained from the AIS scale, accounting for more than $61 \%$ of the total variation, where a latent factor (Kaizer criterion) emerged that explained $50 \%$ of the overall variance for the knowledge management construct. As for organizational performance, over $73 \%$ of the total variance was attributed to the uni-dimensional component. 
Prior to conducting the principal component analysis, the Bartlett's sphericity test was carried out to test the level of correlation between the variables $(p<0.001)$ along with the Kaiser-Meyer-Olkin $(K M O)$ index to verify the suitability of the sample. The Cronbach's alpha coefficient was also calculated to examine the scales' internal reliability as suggested by Osman et al.(2014). The coefficient alpha of the scales ranged from 0.902 to 0.972 indicating that all subscales were higher than the least acceptable reliability level (i.e., 0.7). The number of items and the reliability analysis indices of the entire scales are presented in Table 1, while the results of the Pearson's correlation analysis of the three variables are presented in Table 2.

Table-1. Reliability Analysis and Factor Loading

\begin{tabular}{lcccc}
\hline & Items & $\begin{array}{c}\text { Cronbach's } \\
\text { alpha }\end{array}$ & $\begin{array}{c}\text { \%variance } \\
\text { explained }\end{array}$ & KMOa \\
\hline AIS & 6 & .902 & $61.24 \%$ & .852 \\
Knowledge management & 8 & .932 & $50.1 \%$ & .870 \\
Organization performance & 5 & .972 & $73.4 \%$ & .860 \\
\hline
\end{tabular}

Table-2. Correlation Analysis

\begin{tabular}{lccc}
\hline & AIS & $\begin{array}{c}\text { Knowledge } \\
\text { management }\end{array}$ & $\begin{array}{c}\text { Organisation } \\
\text { performance }\end{array}$ \\
\hline AIS & 1 & & \\
Knowledge management & $.918^{* *}$ & 1 & 1 \\
Organization performance & $.861^{* *}$ & $.985^{* *}$ & \\
& &
\end{tabular}

\subsection{Mediated Regression Analysis}

The results of the mediated regression analysis are presented in Table 3. Three constructs were entered in the analysis namely AIS, knowledge management and organizational performance. The AIS direct and significant relationship with organizational performance was revealed without the effect of knowledge management as proposed in the first hypothesis (H1) (See Model 1) - it explained 35.7\% of the total variance. More specifically, a positive and significant impact was found from AIS to organizational performance (std. beta $=0.397, \mathrm{p}<0.05$ ) indicating that $\mathrm{H} 1$ is supported.

Table-3. Regression results pertaining to the relationship between AIS, knowledge management and organization performance

\begin{tabular}{llll}
\hline Dependent variable & $\begin{array}{l}\text { Organisation } \\
\text { performance } \\
\text { Model 1 } \\
\text { Std. beta }\end{array}$ & $\begin{array}{l}\text { Knowledge } \\
\text { management } \\
\text { Model 2 } \\
\text { Std. beta }\end{array}$ & $\begin{array}{l}\text { Organisation } \\
\text { performance } \\
\text { Model 3 } \\
\text { Std. beta }\end{array}$ \\
\hline AIS & $0.397^{*}$ & $0.471^{* *}$ & 0.164 \\
Knowledge management & - & - & $0.480^{* *}$ \\
\hline Adjusted R square & $.357^{*}$ & $.408^{* *}$ & $0.519^{* * *}$ \\
\hline significant at the 0.05 level, ** significant at the 0.01 level, & $* * *$ significant at the 0.001
\end{tabular}

With regards to $\mathrm{H} 2$, AIS was found to significantly relate to knowledge management (std. beta $=0.471, \mathrm{p}<0.01$ ) explaining $40.8 \%$ of the total variance (See Model 1) indicating support for $\mathrm{H} 2$.

On the basis of the procedures laid down by Hayes (2009), the study analyzed the role of knowledge management in the equation by regressing AIS and knowledge management on organizational performance (See Model 3). In comparison to Model 1, the incremental change in adjusted R-Square was significant and large $(16.4 \%, \mathrm{p}<0.001)$ indicating that knowledge management significantly and directly impacts organizational performance (std. beta $=0.480$, $\mathrm{p}<0.001)$. 
This shows that H3 is supported. Model 3 also reveals that AIS's significant impact on organizational performance was lacking because of the mediating effect (contrasting with Model 1). Thus, the relationship between AIS and organizational performance was found to be fully mediated by knowledge management, explaining the lack of significant effect after the addition of performance in the model. Hence, the proposed mediating model (H4) is also supported.

According to the results, knowledge management was significant in mediating the relationship between AIS and organizational performance, and it is only when knowledge management is improved that AIS can significantly influence organizational performance, indicating support for the mediating model.

\section{Discussion and Conclusions}

In this study, the mediating effect of knowledge management on the relationship between AIS and organizational performance was examined in study sample comprising of 350 employees working in SMEs at the industrial sector. The findings supported the mediating hypothesis, where AIS was found to be a precursor of knowledge management, and knowledge management positively impacted organizational performance. More importantly, the AIS influence on organizational performance can only be possible through enhanced knowledge management.

Thus, SMEs managers in the industrial sector have to employ AIS to enhance knowledge management practices and methods. This is crucial as knowledge management is one of the most important resources to obtain sustainable competitive advantage from. The findings of the current study can be used by future studies to assess the role of several factors including job satisfaction, top management support, leadership and innovativeness.

\section{References}

Abdallah, A. A. J. (2014). The impact of using accounting information systems on the quality of financial statements submitted to the Income and sales tax Department in Jordan. European Scientific Journal, ESJ, 9(10), 41-48.

Amidu, M., Effah, J., \& Abor, J. (2011). E-accounting practices among small and medium enterprises in Ghana. Journal of Management Policy and Practice, 12(4), 146-155.

Baj, Z., Khodadadi, V., \& Ahmadi, M. R. (2014). Relationship between Accounting Information Systems (AIS) and knowledge Management (A case study: Saderat Bank of Behbahan City). Arth prabandh: A Journal of Economics and Management, 3(6), 170-175.

Budiarto, D. S., \& Prabowo, M. A. (2015). Accounting information systems alignment and SMEs performance: A literature review. International Journal of Management, Economics and Social Sciences, 4(2), 58-70.

Chang, T. C., \& Chuang, S. H. (2011). Performance implications of knowledge management processes: Examining the roles of infrastructure capability and business strategy. Expert systems with applications, 38(5), 6170-6178.

Chen, C. J., \& Huang, J. W. (2007). How organizational climate and structure affect knowledge management-The social interaction perspective. International journal of information management, 27(2), 104-118.

Dayan, R., Heisig, P., \& Matos, F. (2017). Knowledge management as a factor for the formulation and implementation of organization strategy. Journal of Knowledge Management, 21(2), 308-329.

Du, R., Ai, S., \& Ren, Y. (2007). Relationship between knowledge sharing and performance: A survey in Xi'an, China. Expert systems with Applications, 32(1), 38-46.

Flynn, B. B., Sakakibara, S., Schroeder, R. G., Bates, K. A., \& Flynn, E. J. (1990). Empirical research methods in operations management. Journal of operations management, 9(2), 250-284.

García-Morales, V. J., Lloréns-Montes, F. J., \& Verdú-Jover, A. J. (2008). The effects of transformational leadership on organizational performance through knowledge and innovation. British journal of management, 19(4), 299319.

Girard, J., \& Girard, J. (2015). Defining knowledge management: Toward an applied compendium. Online Journal of Applied Knowledge Management, 3(1), 1-20.

Gholami, M. H., Asli, M. N., Nazari-Shirkouhi, S., \& Noruzy, A. (2013). Investigating the influence of knowledge management practices on organizational performance: an empirical study. Acta Polytechnica Hungarica, 10(2), 205-216.

Hall, J. A. (2012). Accounting information systems. Cengage Learning.

Harash, E. (2015). The Role of Environmental Uncertainty in the Link between Accounting Information System and Performance Small and Medium Enterprises in Iraq. Global Journal of Management And Business Research, 15(2), 26-32.

Hayes, A. F. (2009). Beyond Baron and Kenny: Statistical mediation analysis in the new millennium. Communication monographs, 76(4), 408-420. 
Hsu, R. C., Lawson, D., \& Liang, T. P. (2007). Factors affecting knowledge management adoption of Taiwan small and medium-sized enterprises. International Journal of Management and Enterprise Development, 4(1), 30-51.

Ismail, N. A. (2009). Factors influencing AIS effectiveness among manufacturing SMEs: Evidence from Malaysia. The Electronic Journal of Information Systems in Developing Countries, 38(1), 1-19.

Kiessling, T. S., Richey, R. G., Meng, J., \& Dabic, M. (2009). Exploring knowledge management to organizational performance outcomes in a transitional economy. Journal of world business, 44(4), 421-433.

Lakshman, C. (2007). Organizational knowledge leadership: A grounded theory approach. Leadership \& Organization Development Journal, 28(1), 51-75.

Mills, A. M., \& Smith, T. A. (2011). Knowledge management and organizational performance: a decomposed view. Journal of knowledge management, 15(1), 156-171.

Mujilan, A. \& U. W. M. Madiun (2012). Sistem Informasi Akuntansi. Teori dan Wawasan Dalam Dunia Ektronis (1st ed.). Madiun: Universitas Widya Mandala Madiun.

Ngah, R., \& Jusoff, K. (2009). Tacit knowledge sharing and SMEs' organizational performance. International Journal of Economics and Finance, 1(1), 216-220.

Noruzy, A., Dalfard, V. M., Azhdari, B., Nazari-Shirkouhi, S., \& Rezazadeh, A. (2013). Relations between transformational leadership, organizational learning, knowledge management, organizational innovation, and organizational performance: an empirical investigation of manufacturing firms. The International Journal of Advanced Manufacturing Technology, 64(5-8), 1073-1085.

Osman, A., Lamis, D. A., Freedenthal, S., Gutierrez, P. M., \& McNaughton-Cassill, M. (2014). The multidimensional scale of perceived social support: Analyses of internal reliability, measurement invariance, and correlates across gender. Journal of Personality Assessment, 96(1), 103-112.

Pollanen, R., Abdel-Maksoud, A., Elbanna, S., \& Mahama, H. (2017). Relationships between strategic performance measures, strategic decision-making, and organizational performance: empirical evidence from Canadian public organizations. Public Management Review, 19(5), 725-746.

Rasula, J., Vuksic, V. B., \& Stemberger, M. I. (2012). The impact of knowledge management on organisational performance. Economic and Business Review for Central and South-Eastern Europe, 14(2), 147-168.

Sačer, I. M., Žager, K., \& Tušek, B. (2006, January). Accounting information system's quality as the ground for quality business reporting. In IADIS International conference, e-commerce 2006.

Slavković, M., \& Babić, V. (2013). Knowledge management, innovativeness, \& organizational performance: Evidence from Serbia. Economic Annals, 58(199), 85-107.

Sori, Z. M. (2009). Accounting information systems (AIS) and knowledge management: a case study. American Journal of scientific research, 4(4), 36-44.

Soudani, S. N. (2012). The usefulness of an accounting information system for effective organizational performance. International Journal of Economics and Finance, 4(5), 136-145.

Susanto, A. (2008). Sistem Informasi Akuntansi, Struktur-Pengendalian-Resiko-Pengembangan. Bandung : Lingga Jaya.

Urquía Gr\&e, E., R. Pérez Estébanez, et al. (2011). The impact of Accounting Information Systems (AIS) on performance measures: empirical evidence in Spanish SMEs. International Journal of Digital Accounting Research, 11, 25-43

Väyrynen, H., Helander, N., \& Kukko, M. (2014). Knowledge management practices in large companies. The Macrotheme Review: a Multidisciplinary Journal of Global Macro Trends, 3(9), 56-72.

Wang, D. H. M., \& Huynh, Q. L. (2013). Mediating role of knowledge management in effect of management accounting practices on firm performance. Journal of Knowledge Management, Economics and Information Technology, 3(3), 1-25.

Zack, M., McKeen, J., \& Singh, S. (2009). Knowledge management and organizational performance: an exploratory analysis. Journal of knowledge management, 13(6), 392-409.

Zaied, A. N. H., Hussein, G. S., \& Hassan, M. M. (2012). The role of knowledge management in enhancing organizational performance. International Journal of Information Engineering and Electronic Business, 4(5), 27-35. 